\title{
Molecular docking of a set of flavonoid compounds with Helicobacter pylori virulence factors CagA and VacA
}

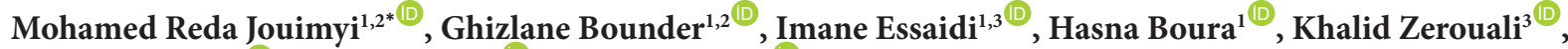 \\ Halima Lebrazi $^{\mathbb{1}}$, Anass Kettani $^{(\mathbb{D}}$, Fatima Maachi ${ }^{1}$ \\ ${ }^{1}$ Laboratory of Helicobacter pylori and Gastric Pathologies, Institut Pasteur du Maroc, Casablanca, Morocco \\ ${ }^{2}$ Laboratory of Biology and Health, Faculty of Sciences Ben M'sik, University Hassan II, Casablanca, Morocco \\ ${ }^{3}$ Microbiology Department, Faculty of Medicine and Pharmacy, University Hassan II, Casablanca, Morocco
}

\section{A R T I C L E I N F O}

Article Type:

Original Article

\section{Article History:}

Received: 2 March 2020

Accepted: 19 June 2020

\section{Keywords:}

CagA

Flavonoids

Helicobacter pylori

Molecular docking

VacA

\begin{abstract}
A B S T R A C T
Introduction: Cytotoxin associated gene A (CagA) and vacuolating cytotoxin A (VacA) proteins are the main Helicobacter pylori virulence factors. These toxins are associated with severe gastric diseases. Flavonoids are plant secondary metabolites that have shown great antibacterial effects. This work aimed to study the interaction of a set of flavonoid compounds with CagA and VacA proteins using molecular docking.

Methods: A set of 54 flavonoid compounds were used in this study, and 36 of which passed the Lipinski rules of 5. The 3D structures of CagA and VacA proteins were obtained from the Protein Data Bank. The molecular docking was performed using AutoDock Vina software and the results were expressed in terms of binding energies $(\mathrm{kcal} / \mathrm{mol})$. Protein-ligand interactions were analyzed using PyMOL software.

Results: For the CagA protein, the licochalcone A molecule showed the highest binding affinity $(-8 \mathrm{kcal} / \mathrm{mol})$. For the VacA protein, the galangin, luteolin, and apigenin molecules showed the highest binding affinity $(-8.9,-8.5$, and $-8.2 \mathrm{kcal} / \mathrm{mol}$, respectively). Interactions of the licochalcone A, galangin, luteolin, and apigenin with CagA and VacA proteins involved their hydroxyl groups and/or their carbonyl groups.

Conclusion: Our study showed that these compounds might have the potential for their development into drugs for controlling H. pylori pathogenicity.
\end{abstract}

Implication for health policy/practice/research/medical education:

Flavonoids are natural molecules produced and used by plants as a defense against biotic stresses. Some of these molecules showed great affinities with $H$. pylori virulence factors (CagA and VacA). Hence, these compounds can be used as candidates for development of new drugs against $H$. pylori.

Please cite this paper as: Jouimyi MR, Bounder G, Essaidi I, Boura H, Zerouali K, Lebrazi H, et al. Molecular docking of a set of flavonoid compounds with Helicobacter pylori virulence factors CagA and VacA. J Herbmed Pharmacol. 2020;9(4):412-419. doi: $10.34172 /$ jhp.2020.52.

\section{Introduction}

Helicobacter pylori is a bacteria that colonizes the stomach of almost half of the world's population (1). Infection with this bacteria is characterized by chronic inflammation of the stomach that can progress to several gastric illnesses such as gastric ulcer, gastric cancer, and MALT lymphoma (2). CagA and VacA proteins are the most studied virulence factors of $H$. pylori and are associated with the severity of gastric diseases. The CagA protein is characterized by a tertiary structure composed of a structured $\mathrm{N}$-terminal region, as well as an intrinsically disordered C-terminal region (3). The $\mathrm{N}$-terminal region of the CagA protein allows it to interact with several host proteins and trigger different signaling pathways (4). The CagA N-terminal region has been shown to bind to the apoptosis-stimulating of $\mathrm{p} 53$ protein 2 (ASPP2), a tumor suppressor protein, causing the inhibition of the p53 protein apoptotic function and activating its degradation (5).

The VacA protein is characterized by the presence of two domains, p33 and p55, involved respectively in the formation of ion channels in the cytoplasmic membrane 
and the binding of the toxin to host cells (6). To date, only the tertiary structure of the p55 domain of the VacA protein has been identified (7).

The emergence of antibiotic-resistant bacteria has become the leading cause of failure in the treatment of infectious diseases (8). The World Health Organization has ranked $H$. pylori among the 12 most resistant bacteria in the world (9). Recently, a promising approach consisting of the inhibition of bacterial virulence factors has emerged (10). Rather than inhibiting the cellular components necessary for the growth or viability of the bacteria, these compounds would decrease the severity of infection by interfering with aspects of bacterial pathogenesis (11).

Since pharmaceutical development relies on natural products to provide biological active components, the screening of natural antibacterial agents has been widely studied and has even become a new engine for the discovery of antibacterial drugs (12-14).

Among these natural molecules, flavonoids are a class of polyphenolic compounds produced by plants as secondary metabolites and act as a defense system against different biotic and abiotic stresses (15). Several studies have shown that flavonoids have antibacterial activity $(10,16,17)$.

Due to the antibacterial effects of flavonoids, a molecular docking study of a set of flavonoid compounds with $H$. pylori virulence factors (CagA and VacA) was performed.

\section{Materials and Methods}

The tertiary structure of CagA and VacA proteins

The tertiary structures of CagA and VacA proteins were obtained from the Protein Data Bank (PDB). For the CagA protein, we used the tertiary structure of the CagA $\mathrm{N}$-terminal region (residues 24-824) resolved by Hayashi with the PDB ID 4DVY (3). The portion of the N-terminal region of the CagA protein (residues 24-221) responsible for its interaction with the ASPP2 protein was isolated using the PyMOL software version 2.0.2 (Figure 1A), and the residues involved in this interaction were selected from Nešić et al study (18).

For the VacA protein, we used the tertiary structure of the p55 domain resolved by Gangwer with the PDB ID 2QV3 (7). The CASTp server was used to determine the best binding site of the VacA protein (19) (Figure 1B).

The residues of the CagA and VacA proteins forming the binding sites are listed in Table 1.

\section{Structural optimization of CagA and VacA proteins}

The tertiary structure of CagA and VacA proteins was optimized using the molecular dynamics simulation software Gromacs version 5.1.2, with the AMBER 99SB force field and the TIP3P water model. The energy minimization consisted of a 6000 step simulation using the steepest descent algorithm. The structures obtained had minimal energy confirmation which ensured their stability. These structures were then used for molecular docking.

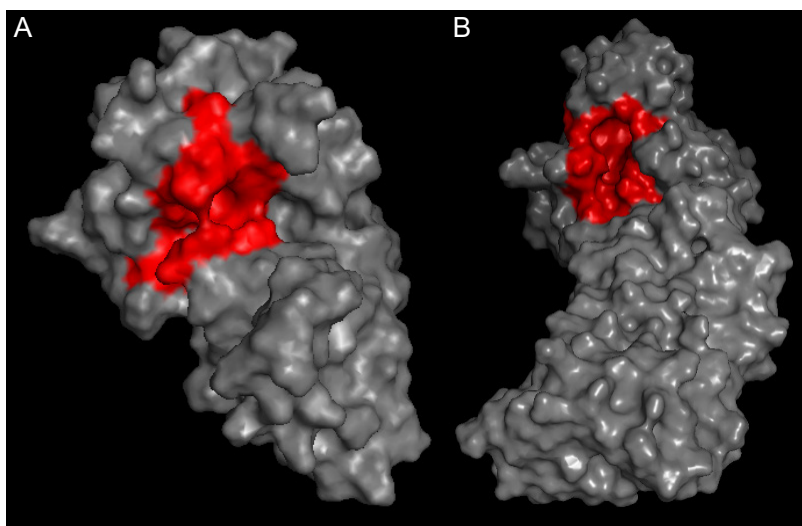

Figure 1. Surface representation of the $\mathrm{N}$-terminal region of the CagA protein (A) and the p55 domain of the VacA protein (B). The binding sites of the CagA and VacA proteins are indicated in red.

Table 1. The binding sites residues of CagA and VacA proteins

\begin{tabular}{ll}
\hline H. pylori virulence factors & Residues forming the binding site \\
\hline \multirow{2}{*}{ CagA } & Phe26, Ile105, Val107, Thr111, Phe114, \\
& Ile175, Trp212, Ile215, Phe219, Phe221 \\
\hline \multirow{3}{*}{ VacA } & Thr641, Asp669, Ala671, Thr672, \\
& Phe674, Tyr675, Lys676, Pro677, Lys680, \\
& Tyr729, Asn733, Arg734, Thr737, \\
& Cys738, Val739, Val740, Arg741, Asp745, \\
& Ala748, Cys749, Ala752 \\
\hline
\end{tabular}

Ligands database

A set of 54 flavonoid compounds obtained from the PubChem database was used in this study (Table 2). Before proceeding with the molecular docking, filtering of these 54 flavonoid compounds was carried out based on the Lipinski rules of 5 (20) using the Molinspiration online server. This step makes it possible to keep the compounds capable of fulfilling the criteria of absorption, distribution, metabolism, and excretion, essential for a compound to be considered as a potentially active drug orally in the human body.

\section{Molecular docking}

The AutoDock Vina software version 1.1.2 was used for molecular docking of flavonoid compounds with CagA and VacA proteins. The grid box enclosing the CagA and VacA proteins binding sites were calculated using the AutoDock Vina plug-in available on PyMOL and developed by Daniel Seeliger. The position and dimensions of the box are shown in Table 3. Molecular docking results were expressed in terms of binding energies ( $\mathrm{kcal} / \mathrm{mol}$ ), and protein-ligand interactions were analyzed using PyMOL software version 2.0.2.

\section{Results}

Analysis of bioavailability of the flavonoid compounds The bioavailability analysis of the 54 flavonoid compounds 
Table 2. Names, PubChem ID, and the status of the Lipinski rules of 5 of the 54 flavonoid compounds used in this study

\begin{tabular}{|c|c|c|}
\hline Compounds names & PubChem ID & 5 Lipinski rules status \\
\hline Abyssinones & 10408069 & Fail \\
\hline Apigenin & 5280443 & Pass \\
\hline Baicalein & 5281605 & Pass \\
\hline Baicalin & 64982 & Fail \\
\hline Bartericin A & 12136209 & Fail \\
\hline Biochanin & 5280373 & Pass \\
\hline Catechin & 9064 & Pass \\
\hline Chrysin & 5281607 & Pass \\
\hline Daidzein & 5281708 & Pass \\
\hline Daidzin & 107971 & Pass \\
\hline Dihydromyricetin & 161557 & Fail \\
\hline Diosmetin & 5281612 & Pass \\
\hline Epicatechin & 72276 & Pass \\
\hline Epigallocatechin & 72277 & Fail \\
\hline Eriodictyol & 440735 & Pass \\
\hline Fisetin & 5281614 & Pass \\
\hline Flavone & 10680 & Pass \\
\hline Flavylium & 145858 & Pass \\
\hline Formononetin & 5280378 & Pass \\
\hline Galangin & 5281616 & Pass \\
\hline Genistein & 5280961 & Pass \\
\hline Genistin & 5281377 & Fail \\
\hline Hesperidin & 10621 & Fail \\
\hline Hesperitin & 72281 & Pass \\
\hline Isobavachalcone & 5281255 & Pass \\
\hline Isolupalbigenin & 26238934 & Fail \\
\hline Isoorientin & 114776 & Fail \\
\hline Kaempferol & 5280863 & Pass \\
\hline Licochalcone A & 5318998 & Pass \\
\hline Luteolin & 5280445 & Pass \\
\hline Macluraxanthone & 5281646 & Fail \\
\hline 3'-O-Methyldiplacol & 21607150 & Pass \\
\hline Morin & 5281670 & Pass \\
\hline Myricetin & 5281672 & Fail \\
\hline Myricitrin & 5281673 & Fail \\
\hline Naringenin & 932 & Pass \\
\hline Naringin & 442428 & Fail \\
\hline Nobiletin & 72344 & Pass \\
\hline Panduratin A & 6483648 & Fail \\
\hline Peonidin & 164544 & Pass \\
\hline Puerarin & 5281807 & Fail \\
\hline Quercetin & 5280343 & Pass \\
\hline Rutin & 5280805 & Fail \\
\hline Sakuranetin & 73571 & Pass \\
\hline Scopoletin & 5280460 & Pass \\
\hline Scutellarein & 5281697 & Pass \\
\hline Tangeritin & 68077 & Pass \\
\hline Taxifolin & 439533 & Pass \\
\hline 3,5,6,7-Tetramethoxyflavone & 471721 & Pass \\
\hline Theaflavin & 135403798 & Fail \\
\hline Tricin & 5281702 & Pass \\
\hline Trihydroxyflavone & 17840571 & Pass \\
\hline Warangalone & 5379679 & Fail \\
\hline Wogonin & 5281703 & Pass \\
\hline
\end{tabular}

Table 3. Docking box parameters used in this study

\begin{tabular}{lcccccc}
\hline \multirow{2}{*}{$\begin{array}{l}\text { H. pylori virulence } \\
\text { factors }\end{array}$} & \multicolumn{3}{c}{ Box dimensions in $\AA^{2}$} & \multicolumn{3}{c}{ Box coordinates in $\AA^{2}$} \\
\cline { 2 - 7 } & $\mathbf{X}$ & $\mathbf{Y}$ & $\mathbf{Z}$ & $\mathbf{X}$ & $\mathbf{Y}$ & $\mathbf{Z}$ \\
\hline CagA & 68 & 69 & 51 & 51.11 & 55.11 & 54.1 \\
VacA & 64 & 64 & 73 & 58.73 & 81.74 & 47.73 \\
\hline
\end{tabular}

by the Lipinski rules of 5 showed that 36 compounds met all criteria (Table 2). These compounds were then used for molecular docking.

Analysis of molecular docking results

For the CagA N-terminal region, the licochalcone A molecule (Figure 2) showed the highest binding energy $(-8 \mathrm{kcal} / \mathrm{mol})$. The hydroxyl groups at the 4 and 4 ' positions located respectively on the $\mathrm{A}$ and $\mathrm{B}$ rings of licochalcone A interacted with the Gln 120 hydrogen atom and Gln170 oxygen atom of the CagA N-terminal region with distances of 2.1 and $2.5 \AA^{2}$, respectively (Figure 3 ). For the VacA protein, the galangin, luteolin, and apigenin molecules (Figure 2) showed the highest binding energies $(-8.9,-8.5$, and $-8.2 \mathrm{kcal} / \mathrm{mol}$, respectively).

The interaction of the galangin with the VacA protein involved its hydroxyl and carbonyl groups. The hydroxyl group at position 3 of the $\mathrm{C}$ ring interacted with the Thr737 oxygen atom with a distance of $2.1 \AA^{2}$. This same hydroxyl group interacted also with the Val739 oxygen and hydrogen atoms with distances of 3.2 and $2.5 \AA^{2}$, respectively. Also, the Val739 hydrogen atom interacted with the galangin carbonyl group located at position 4 of the $\mathrm{C}$ ring with a distance of $2.2 \AA^{2}$. Finally, the galangin hydroxyl group at positions 5 and 7 of the A ring interacted respectively with the Asp745 oxygen atoms with distances of 2.3 and $2.6 \AA^{2}$ (Figure 4 ).

The interaction of luteolin with the VacA protein involved its hydroxyl groups. The hydroxyl group located at the 5 position of the A ring interacts with the Tyr729 hydrogen atom with a distance of $1.8 \AA^{2}$, while the hydroxyl group located at the 3 ' position of the $\mathrm{B}$ ring interacted with the Asp745 oxygen atom with a distance of $2.1 \AA^{2}$ (Figure 5).<smiles>O=c1c(O)c(-c2ccccc2)oc2cc(O)cc(O)c12</smiles><smiles>C=CC(C)(C)c1cc(/C=C/C(=O)c2ccc(O)cc2)c(OC)cc1O</smiles>

Figure 2. The two-dimensional structure of the flavonoid compounds with the high binding energies from molecular docking. 


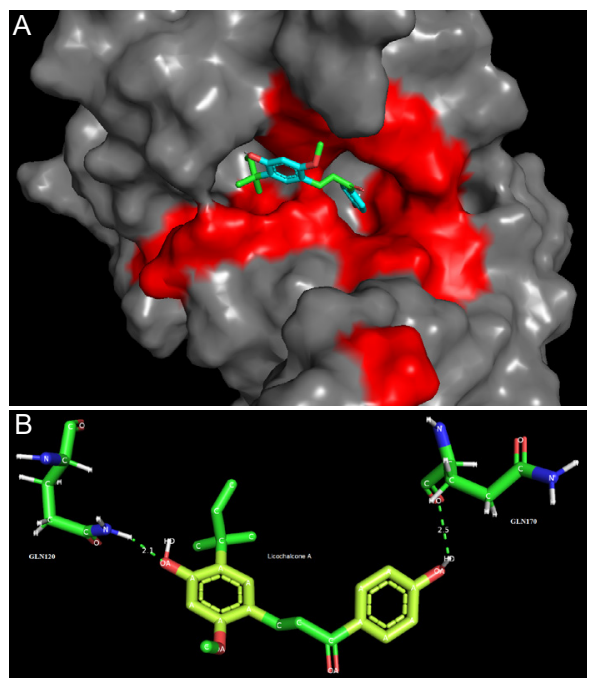

Figure 3. Interaction of licochalcone A molecule (sticks) with the CagA $\mathrm{N}$-terminal region (surface mode) (A). Interaction of licochalcone $\mathrm{A}$ molecule with the $\mathrm{G} \ln 120$ and $\mathrm{G} \ln 170$ amino acids of the CagA N-terminal region (B).

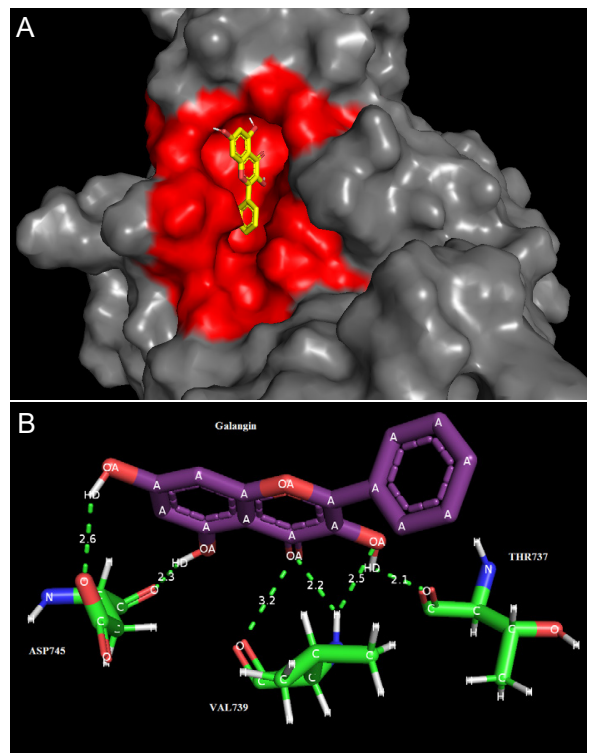

Figure 4. Interaction of the galangin molecule (sticks) with the VacA protein (surface mode) (A). Interaction of the galangin molecule with the amino acids Thr737, Val739, and Asp745 of the VacA protein (B).

The interaction of apigenin with the VacA protein involved its carbonyl and hydroxyl groups. The carbonyl group at the 4 position of the $\mathrm{C}$ ring interacted with the Arg734 hydrogen atom with a distance of $2.2 \AA^{2}$. The hydroxyl group at the 4' position of the $\mathrm{B}$ ring interacted with the Asp745 oxygen atom with a distance of $2.3 \AA^{2}$, and the hydroxyl group at the 7 position of the A ring interacted with the Lys680 hydrogen atom with a distance of $2.5 \AA^{2}$ (Figure 6).
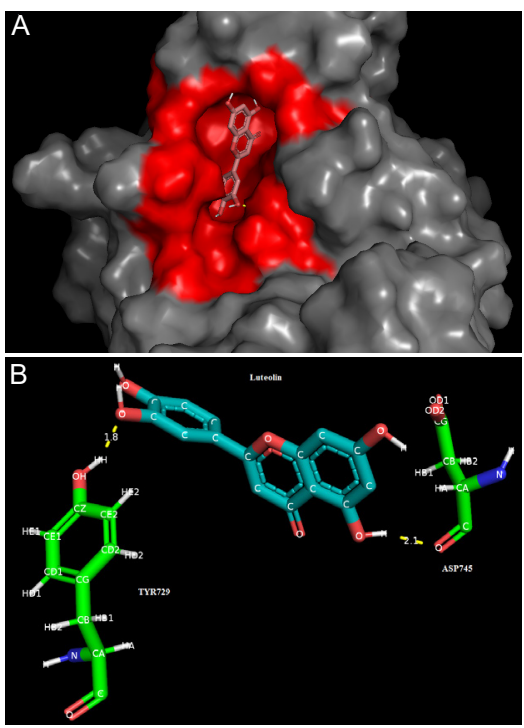

Figure 5. Interaction of luteolin molecule (sticks) with the VacA protein (surface mode) (A). Interaction of luteolin with the amino acids Tyr729 and Asp745 of the VacA protein (B).
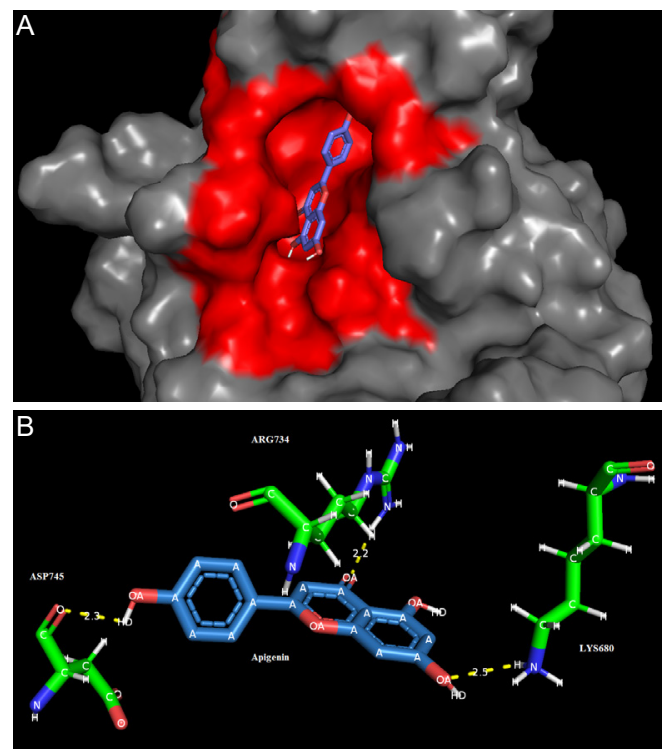

Figure 6. Interaction of apigenin molecule (sticks) with the VacA protein (surface mode) (A). Interaction of apigenin molecule with the amino acids Lys680, Arg734, and Asp745 of the VacA protein (B).

\section{Discussion}

The inefficiency of currently available antibiotics encourages the search for new antibacterial agents capable of countering this growing resistance. The efficacy of the treatment for the eradication of $H$. pylori infection has decreased considerably due to the resistance of this bacterium to antibiotics $(21,22)$. H. pylori resistance rate to antibiotics (clarithromycin, metronidazole, and levofloxacin) exceeded the rate of $15 \%$ in almost 65 countries (9). The antibacterial effects of flavonoids 
include inhibition of bacterial attachment to host receptors, inhibition of biofilm formation, and neutralization of bacterial toxins $(23,24)$. Several works have reported a flavonoid inhibitory activity against $H$. pylori (25-28). The antibacterial potential of flavonoids led us to study the interaction of a set of flavonoid compounds with the main H. pylori virulence factors (CagA and VacA).

The docking of the 36 flavonoid molecules with the CagA N-terminal region showed that the licochalcone A molecule had the highest binding energy. Licochalcone A, derived from the licorice root (Glycyrrhiza glabra or Glycyrrhiza radix), is a flavonoid belonging to the chalcones family and used for the treatment of gastric ulcers and inflammations $(29,30)$. The antibacterial effects of chalcones against several bacterial species, including $H$. pylori, have been shown by multiple studies (31-35).

In our study, the interaction of licochalcone A with the CagA N-terminal region involved their hydroxyl groups. The antibacterial activity of flavonoids depends on their structures, precisely the substitutions on their aromatic cycles. Indeed, authors have shown that hydroxyl groups at the 4 and 4 ' positions of the $\mathrm{A}$ and $\mathrm{B}$ rings are essential for the antibacterial activity of chalcones (36-38). It was shown that chalcones extracted from the licorice root (licochalcone A and licochalcone E) inhibit bacterial infection by decreasing their gene expression, inhibiting their growth, and reducing their toxin production (39). The licochalcone A showed an inhibitory effect against the growth of $H$. pylori, even on resistant strains (40).

Galangin was the molecule with the highest binding energy with VacA protein. This molecule belongs to the class of flavonols and is present in the small galanga (Alpinia officinarum) and propolis. Galangin has excellent anti-cancer, anti-inflammatory, and antioxidants effects (41-43).

Interaction of galangin with the VacA protein involved its hydroxyl and carbonyl groups on the $\mathrm{C}$ ring as well as the hydroxyl group on the A ring. It was shown that hydroxyl groups on the $\mathrm{A}$ (at 5 and 7 positions), $\mathrm{B}$, and $\mathrm{C}$ rings increased the antibacterial activities of flavonols $(44,45)$. However, the hydroxylation of the $\mathrm{B}$ ring at position 4' decreases this effect (46). The galangin molecule is characterized by multiple hydroxylation groups at A (at 5 and 7 positions) and $C$ rings (at 3 position). As a result, significant antibacterial effects of this molecule have been reported by several studies (47-50).

The other two compounds (luteolin and apigenin) with good binding energy to the VacA protein belong to the class of flavones. Luteolin is a molecule found in several vegetables (carrots, peppers, celery, olive oil) and medicinal plants (51), and has several biological effects such as antioxidant, anti-cancer, and anti-inflammatory effects (51). The interaction of luteolin with the VacA protein showed binding energy of $-8.5 \mathrm{kcal} / \mathrm{mol}$. Numerous studies have reported the antibacterial activity of luteolin on several bacterial species (52-54). An inhibitory effect of this molecule on the growth of $H$. pylori has been demonstrated (55). In this study, the luteolin molecule interacted with the VacA protein by its hydroxyl groups. Although the antibacterial effects of luteolin have been demonstrated in several studies, the structure-activity mechanism of this molecule is still unknown. The antibacterial effect of a given flavonoid is determined by the number and the positions of its hydroxyl groups on its rings (15). In the case of flavones, possessing at least one hydroxyl group in the A ring (at position 7) is vital for the antibacterial activity, and in other positions (5 and 6) can increase this effect (56). Hence, the presence of hydroxyl groups in positions 5 and 7 of the A ring could confer to luteolin a significant antibacterial effect, which may also explain its high binding energy.

The apigenin molecule is among the most common flavonoids in the plant kingdom (57). It is mainly found in vegetables (parsley, celery, onions), fruits (oranges), herbs (chamomile, thyme, oregano, basil) and herbal drinks (tea, beer, wine) (58). The apigenin was shown to have multiple biological properties including anti-cancer, antiinflammatory, and antioxidant effects (59-64).

The apigenin molecule interacts with the VacA protein by its hydroxyl and carbonyl groups. The potent antibacterial activity of the apigenin against a number of bacteria has been assessed by several studies (65-67). As discussed above, the antibacterial activity of flavones is directed by the number and positions of the hydroxyl groups they contain. The hydroxylation at position 7 of the A ring is required for the antimicrobial activity of flavones. As a result, the hydroxyl groups of apigenin could be at the origin of its antibacterial activity.

Numerous works have investigated the interaction of natural molecules against $H$. pylori virulence factors. In vitro and in vivo studies suggest that isoflavone, flavonol, and chalcone compounds inhibit the urease activity, which plays an important role in the colonization of the gastric mucosa by $H$. pylori $(26-28,68)$. Several flavone derivatives and other polyphenols present in vegetables and plants inhibit ionic conduction and urea by H. pylori, as well as vacuolization induced by the VacA protein (25). Moreover, Srivastava et al studied the molecular docking of the curcumin molecule with $H$. pylori virulence factors (CagA, VacA, and urease), and showed that this molecule presents good affinities with the urease (69). All these studies converge toward the idea that the approach of neutralizing bacterial virulence factors may be an alternative to the strategy commonly used in the treatment of infectious diseases, which could have an impact on reducing the high antibiotic resistance rate, specifically for $H$. pylori infection.

\section{Conclusion}

Our study showed that from the 36 flavonoids molecules 
that passed the Lipinski rules of 5 , the licochalcone A molecule showed the highest binding affinity with the CagA protein, while the galangin, luteolin, and apigenin molecules showed the highest binding affinity with the VacA protein. We also demonstrated that interactions of all of these molecules with CagA and VacA proteins involved their hydroxyl and/or their carbonyl groups, which are essentials for their antibacterial activity. Therefore, it seems that these molecules could play an inhibitory role in the signaling and recognition processes induced by CagA and VacA proteins, and thus may be used as potential candidates for designing new antibiotics.

\section{Authors' contributions}

MRJ, AK, and FM designed the study. MRJ carried out the study and wrote the manuscript. GB, IE, HB, KZ, and HL revised the manuscript. All authors read and approved the final version of the manuscript.

\section{Conflict of interests}

Authors declare no conflict of interest.

\section{Ethical considerations}

No ethical approval was required for the conduct of this study. Text plagiarism, misconduct, manipulation or appropriation, data fabrication, falsification, redundant publication as well as duplicate submissions have been carefully observed by authors.

\section{Funding/Support}

This research was financially supported by Laboratory of Helicobacter pylori and Gastric Pathologies, Institut Pasteur du Maroc, Casablanca, Morocco.

\section{References}

1. Kusters JG, van Vliet AHM, Kuipers EJ. Pathogenesis of Helicobacter pylori infection. Clin Microbiol Rev. 2006;19(3):449-90.

2. Wroblewski LE, Peek RM, Wilson KT. Helicobacter pylori and gastric cancer: factors that modulate disease risk. Clin Microbiol Rev. 2010;23(4):713-39. doi: 10.1128/ CMR.00011-10.

3. Hayashi T, Senda M, Morohashi H, Higashi H, Horio M, Kashiba Y, et al. Tertiary structure-function analysis reveals the pathogenic signaling potentiation mechanism of Helicobacter pylori oncogenic effector CagA. Cell Host Microbe. 2012;12(1):20-33. doi: 10.1016/j. chom.2012.05.010.

4. Hatakeyama M. Structure and function of Helicobacter pylori CagA, the first-identified bacterial protein involved in human cancer. Proc Jpn Acad Ser B Phys Biol Sci. 2017;93(4):196-219.

5. Buti L, Spooner E, Van der Veen AG, Rappuoli R, Covacci A, Ploegh HL. Helicobacter pylori cytotoxin-associated gene A (CagA) subverts the apoptosis-stimulating protein of $\mathrm{p} 53$ (ASPP2) tumor suppressor pathway of the host. Proc Natl Acad Sci U S A. 2011;108(22):9238-43.
6. Nejati S, Karkhah A, Darvish H, Validi M, Ebrahimpour $S$, Nouri HR. Influence of Helicobacter pylori virulence factors CagA and VacA on pathogenesis of gastrointestinal disorders. Microb Pathog. 2018;117:43-8.

7. Gangwer KA, Mushrush DJ, Stauff DL, Spiller B, McClain MS, Cover TL, et al. Crystal structure of the Helicobacter pylori vacuolating toxin p55 domain. Proc Natl Acad Sci U S A. 2007;104(41):16293-8.

8. Alanis AJ. Resistance to antibiotics: are we in the postantibiotic era? Arch Med Res. 2005;36(6):697-705.

9. Savoldi A, Carrara E, Graham DY, Conti M, Tacconelli E. Prevalence of antibiotic resistance in Helicobacter pylori: A systematic review and Meta-analysis in World Health Organization regions. Gastroenterology. 2018;155(5):13721382.e17. doi: 10.1053/j.gastro.2018.07.007.

10. Cushnie TPT, Lamb AJ. Recent advances in understanding the antibacterial properties of flavonoids. Int J Antimicrob Agents. 2011;38(2):99-107. doi: 10.1016/j. ijantimicag.2011.02.014.

11. Cegelski L, Marshall GR, Eldridge GR, Hultgren SJ. The biology and future prospects of antivirulence therapies. Nat Rev Microbiol. 2008;6(1):17-27.

12. Newman DJ, Cragg GM. Natural products as sources of new drugs over the 30 years from 1981 to 2010. J Nat Prod. 2012;75(3):311-35. doi: 10.1021/np200906s.

13. Taylor PW. Alternative natural sources for a new generation of antibacterial agents. Int J Antimicrob Agents. 2013;42(3):195-201.

14. Brown DG, Lister T, May-Dracka TL. New natural products as new leads for antibacterial drug discovery. Bioorg Med Chem Lett. 2014;24(2):413-8.

15. Kumar S, Pandey AK. Chemistry and biological activities of flavonoids: An overview. Sci World J. 2013;2013:162750. doi: $10.1155 / 2013 / 162750$

16. Cushnie TPT, Lamb AJ. Antimicrobial activity of flavonoids. Int J Antimicrob Agents. 2005;26(5):343-56.

17. Orhan DD, Ozçelik B, Ozgen S, Ergun F. Antibacterial, antifungal, and antiviral activities of some flavonoids. Microbiol Res. 2010;165(6):496-504.

18. Nešić D, Buti L, Lu X, Stebbins CE. Structure of the Helicobacter pylori CagA oncoprotein bound to the human tumor suppressor ASPP2. Proc Natl Acad Sci U S A. 2014;111(4):1562-7. doi: 10.1073/pnas.1320631111.

19. Tian W, Chen C, Lei X, Zhao J, Liang J. CASTp 3.0: computed atlas of surface topography of proteins. Nucleic Acids Res. 2018;46(W1):W363-7. doi: 10.1093/nar/gky473.

20. Lipinski CA, Lombardo F, Dominy BW, Feeney PJ. Experimental and computational approaches to estimate solubility and permeability in drug discovery and development settings. Adv Drug Deliv Rev. 2001;46(1):326.

21. Bang CS, Baik GH. Attempts to enhance the eradication rate of Helicobacter pylori infection. World J Gastroenterol. 2014;20(18):5252-62. doi: 10.3748/wjg.v20.i18.5252.

22. Kim SY, Choi DJ, Chung J-W. Antibiotic treatment for Helicobacter pylori: Is the end coming? World J Gastrointest Pharmacol Ther. 2015;6(4):183-98.

23. Choi KD, Kim N, Lee DH, Kim JM, Kim JS, Jung HC, et al. Analysis of the 3' variable region of the cagA gene of Helicobacter pylori isolated in Koreans. Dig Dis Sci. 
2007;52(4):960-6.

24. Oh D-R, Kim JR, Kim YR. Genistein inhibits vibrio vulnificus adhesion and cytotoxicity to HeLa cells. Arch Pharm Res. 2010;33(5):787-92. doi: 10.1007/s12272-0100520-y.

25. Tombola F, Campello S, De Luca L, Ruggiero P, Del Giudice G, Papini E, et al. Plant polyphenols inhibit VacA, a toxin secreted by the gastric pathogen Helicobacter pylori. FEBS Lett. 2003;543(1-3):184-9.

26. Isomoto H, Furusu H, Ohnita K, Wen CY, Inoue K, Kohno S. Sofalcone, a mucoprotective agent, increases the cure rate of Helicobacter pylori infection when combined with rabeprazole, amoxicillin and clarithromycin. World J Gastroenterol. 2005;11(11):1629-33.

27. Xiao Z-P, Shi D-H, Li H-Q, Zhang L-N, Xu C, Zhu H-L. Polyphenols based on isoflavones as inhibitors of Helicobacter pylori urease. Bioorg Med Chem. 2007;15(11):3703-10. doi: 10.1016/j.bmc.2007.03.045.

28. González-Segovia R, Quintanar JL, Salinas E, CeballosSalazar R, Aviles-Jiménez F, Torres-López J. Effect of the flavonoid quercetin on inflammation and lipid peroxidation induced by Helicobacter pylori in gastric mucosa of guinea pig. J Gastroenterol. 2008;43(6):441-7.

29. Shibata S. A drug over the millennia: pharmacognosy, chemistry, and pharmacology of licorice. Yakugaku Zasshi. 2000;120(10):849-62.

30. Baltina LA. Chemical modification of glycyrrhizic acid as a route to new bioactive compounds for medicine. Curr Med Chem. 2003;10(2):155-71.

31. Tsukiyama R-I, Katsura H, Tokuriki N, Kobayashi M. Antibacterial activity of licochalcone A against sporeforming bacteria. Antimicrob Agents Chemother. 2002;46(5):1226-30. doi: 10.1128/aac.46.5.1226-1230.2002.

32. Friis-Møller A, Chen M, Fuursted K, Christensen SB, Kharazmi A. In vitro antimycobacterial and antilegionella activity of licochalcone A from Chinese licorice roots. Planta Med. 2002;68(5):416-9. doi: 10.1055/s-2002-32087.

33. Kuete V, Simo IK, Ngameni B, Bigoga JD, Watchueng J, Kapguep RN, et al. Antimicrobial activity of the methanolic extract, fractions and four flavonoids from the twigs of Dorstenia angusticornis Engl. (Moraceae). J Ethnopharmacol. 2007;112(2):271-7.

34. Zhu Y, Zhang P, Yu H, Li J, Wang M-W, Zhao W. AntiHelicobacter pylori and thrombin inhibitory components from Chinese dragon's blood, Dracaena cochinchinensis. J Nat Prod. 2007;70(10):1570-7. doi: 10.1021/np070260v.

35. Sufian AS, Ramasamy K, Ahmat N, Zakaria ZA, Yusof MIM. Isolation and identification of antibacterial and cytotoxic compounds from the leaves of Muntingia calabura L. J Ethnopharmacol. 2013;146(1):198-204.

36. Nielsen SF, Boesen T, Larsen M, Schønning K, Kromann $H$. Antibacterial chalcones--bioisosteric replacement of the 4'-hydroxy group. Bioorg Med Chem. 2004;12(11):304754 .

37. Nowakowska Z. A review of anti-infective and antiinflammatory chalcones. Eur J Med Chem. 2007;42(2):12537.

38. Sahu NK, Balbhadra SS, Choudhary J, Kohli DV. Exploring pharmacological significance of chalcone scaffold: a review. Curr Med Chem. 2012;19(2):209-25.
39. Wang L, Yang R, Yuan B, Liu Y, Liu C. The antiviral and antimicrobial activities of licorice, a widely-used Chinese herb. Acta Pharm Sin B. 2015;5(4):310-5.

40. Fukai T, Marumo A, Kaitou K, Kanda T, Terada S, Nomura T. Anti-Helicobacter pylori flavonoids from licorice extract. Life Sci. 2002;71(12):1449-63.

41. Heo MY, Sohn SJ, Au WW. Anti-genotoxicity of galangin as a cancer chemopreventive agent candidate. Mutat Res. 2001;488(2):135-50.

42. Sivakumar AS, Anuradha CV. Effect of galangin supplementation on oxidative damage and inflammatory changes in fructose-fed rat liver. Chem Biol Interact. 2011;193(2):141-8. doi: 10.1016/j.cbi.2011.06.003.

43. Jung YC, Kim ME, Yoon JH, Park PR, Youn H-Y, Lee $\mathrm{H}-\mathrm{W}$, et al. Anti-inflammatory effects of galangin on lipopolysaccharide-activated macrophages via ERK and NF$\kappa \mathrm{B}$ pathway regulation. Immunopharmacol Immunotoxicol. 2014;36(6):426-32. doi: 10.3109/08923973.2014.968257.

44. Woźnicka E, Kuźniar A, Nowak D, Nykiel E, Kopacz M, Gruszecka J, et al. Comparative study on the antibacterial activity of some flavonoids and their sulfonic derivatives. Acta Pol Pharm. 2013;70(3):567-71.

45. Farhadi F, Khameneh B, Iranshahi M, Iranshahy M. Antibacterial activity of flavonoids and their structureactivity relationship: An update review. Phytother Res. 2019;33(1):13-40.

46. Echeverría J, Opazo J, Mendoza L, Urzúa A, Wilkens M. Structure-activity and lipophilicity relationships of selected antibacterial natural flavones and flavanones of Chilean flora. Mol Basel Switz. 2017;22(4):1-15. doi: 10.3390/ molecules22040608.

47. Cushnie TPT, Hamilton VES, Lamb AJ. Assessment of the antibacterial activity of selected flavonoids and consideration of discrepancies between previous reports. Microbiol Res. 2003;158(4):281-9.

48. Pepeljnjak S, Kosalec I. Galangin expresses bactericidal activity against multiple-resistant bacteria: MRSA, Enterococcus spp. and Pseudomonas aeruginosa. FEMS Microbiol Lett. 2004;240(1):111-6.

49. Cushnie TPT, Lamb AJ. Assessment of the antibacterial activity of galangin against 4-quinolone resistant strains of Staphylococcus aureus. Phytomedicine Int J Phytother Phytopharm. 2006;13(3):187-91.

50. Eumkeb G, Sakdarat S, Siriwong S. Reversing $\beta$-lactam antibiotic resistance of Staphylococcus aureus with galangin from Alpinia officinarum Hance and synergism with ceftazidime. Phytomedicine Int J Phytother Phytopharm. 2010;18(1):40-5.

51. López-Lázaro M. Distribution and biological activities of the flavonoid luteolin. Mini Rev Med Chem. 2009;9(1):3159.

52. Lee K-A, Moon SH, Kim K-T, Mendonca AF, Paik H-D, Antimicrobial effects of various flavonoids on Escherichia coli O157:H7 cell growth and lipopolysaccharide production. Food Sci Biotechnol. 2010;19(1):257-61.

53. Su Y, Ma L, Wen Y, Wang H, Zhang S. Studies of the in vitro antibacterial activities of several polyphenols against clinical isolates of methicillin-resistant Staphylococcus aureus. Mol Basel Switz. 2014;19(8):12630-9.

54. Usman Amin M, Khurram M, Khan TA, Faidah HS, 
Ullah Shah Z, Ur Rahman S, et al. Effects of Luteolin and Quercetin in Combination with Some Conventional Antibiotics against Methicillin-Resistant Staphylococcus aureus. Int J Mol Sci. 2016;17(11):1-16.

55. Chung JG, Hsia TC, Kuo HM, Li YC, Lee YM, Lin SS, et al. Inhibitory actions of luteolin on the growth and arylamine $\mathrm{N}$-acetyltransferase activity in strains of Helicobacter pylori from ulcer patients. Toxicol In Vitro. 2001;15(3):191-8.

56. Wu T, He M, Zang X, Zhou Y, Qiu T, Pan S, et al. A structureactivity relationship study of flavonoids as inhibitors of $\mathrm{E}$. coli by membrane interaction effect. Biochim Biophys Acta BBA - Biomembr. 2013;1828(11):2751-6.

57. Salehi B, Venditti A, Sharifi-Rad M, Kręgiel D, Sharifi-Rad J, Durazzo A, et al. The Therapeutic Potential of Apigenin. Int J Mol Sci. 2019;20(6):1-26.

58. Hostetler GL, Ralston RA, Schwartz SJ. Flavones: Food Sources, Bioavailability, Metabolism, and Bioactivity. Adv Nutr Bethesda Md. 2017;8(3):423-35. doi: 10.3945/ an.116.012948.

59. Mira L, Fernandez MT, Santos M, Rocha R, Florêncio $\mathrm{MH}$, Jennings KR. Interactions of flavonoids with iron and copper ions: a mechanism for their antioxidant activity. Free Radic Res. 2002;36(11):1199-208.

60. Chiang L-C, Ng LT, Lin I-C, Kuo P-L, Lin C-C. Antiproliferative effect of apigenin and its apoptotic induction in human Hep G2 cells. Cancer Lett. 2006;237(2):207-14.

61. Chan L-P, Chou T-H, Ding H-Y, Chen P-R, Chiang F-Y, Kuo $\mathrm{P}-\mathrm{L}$, et al. Apigenin induces apoptosis via tumor necrosis factor receptor- and Bcl-2-mediated pathway and enhances susceptibility of head and neck squamous cell carcinoma to 5-fluorouracil and cisplatin. Biochim Biophys Acta. 2012;1820(7):1081-91. doi: 10.1016/j.bbagen.2012.04.013.
62. Wang J, Liu Y-T, Xiao L, Zhu L, Wang Q, Yan T. Antiinflammatory effects of apigenin in lipopolysaccharideinduced inflammatory in acute lung injury by suppressing COX-2 and NF-kB pathway. Inflammation. 2014;37(6):2085-90. doi: 10.1007/s10753-014-9942-x.

63. An F, Cao X, Qu H, Wang S. Attenuation of oxidative stress of erythrocytes by the plant-derived flavonoids vitexin and apigenin. Pharmazie. 2015;70(11):724-32.

64. Basios N, Lampropoulos P, Papalois A, Lambropoulou M, Pitiakoudis MK, Kotini A, et al. Apigenin attenuates inflammation in experimentally induced acute pancreatitisassociated lung injury. J Investig Surg J Acad Surg Res. 2016;29(3):121-7. doi: 10.3109/08941939.2015.1088603.

65. Nayaka HB, Londonkar RL, Umesh MK, Tukappa A. Antibacterial Attributes of Apigenin, Isolated from Portulaca oleracea L. Int J Bacteriol. 2014;2014:1-8.

66. Morimoto Y, Baba T, Sasaki T, Hiramatsu K. Apigenin as an anti-quinolone-resistance antibiotic. Int J Antimicrob Agents. 2015;46(6):666-73. doi: 10.1016/j. ijantimicag.2015.09.006.

67. Cha S-M, Kim G-U, Cha J-D. Synergistic antimicrobial activity of apigenin against oral Pathogens. Int J Eng Res Sci. 2016;2(1):27-37.

68. Ansari FL, Umbreen S, Hussain L, Makhmoor T, Nawaz SA, Lodhi MA, et al. Syntheses and biological activities of chalcone and 1,5-benzothiazepine derivatives: promising new free-radical scavengers, and esterase, urease, and alphaglucosidase inhibitors. Chem Biodivers. 2005;2(4):487-96.

69. Srivastava AK, Kumar V, Roy BK. Insights from the molecular docking of curcumin to the virulent factors of Helicobacter pylori. Bioinformation. 2015;11(10):447-53. doi: $\quad 10.6026 / 97320630011447$. 